\title{
Acoustical and Thermodynamical Properties of Ternary Liquid Mixtures at 303.15 K
}

\author{
S.THIRUMARAN*, R.MATHAMMAL and P.THENMOZHI
}

*Department of Physics (DDE), Annamalai University, Annamalai Nagar-608 002, India

Department of Physics, Sri Saradha College for Women, (Autonomous),

Salem- 636 016, India

thirumaran64@gmail.com

Received 4 June 2012 / Accepted 22 June 2012

\begin{abstract}
The observed experimental parameters such as density $(\rho)$, viscosity $(\eta)$ and ultrasonic velocity (U) of ternary liquid mixtures of primary alkanols such as 1-propanol, 1-butanol, 1-pentanol and 1-hexanol with $N$ - $N$ dimethylfomamide (DMF) in acetophenone at $303.15 \mathrm{~K}$ were determined. The observed experimental data have been utilized to evaluate some of the thermo acoustical parameters and also their excess values such as adiabatic compressibility $\left(\beta^{\mathrm{E}}\right)$, intermolecular free length $\left(\mathrm{L}_{\mathrm{f}}^{\mathrm{E}}\right)$, free volume $\left(V_{f}^{E}\right)$, internal pressure $\left(\pi_{i}^{E}\right)$, Gibb's energy $\left(\Delta G^{E}\right)$ and viscosity $\left(\eta^{\mathrm{E}}\right)$. Our present investigation observes that the interaction between DMF (Proton acceptor) and 1-alkanols is due to hydrogen bonding. There seems to be a dissociation of associated structure of 1-alkanols and decrease in interaction (hydrogen bonding) between acetophenone and 1-alkanols on further addition of DMF. It is also noticed that on further addition of DMF leads to subsequent decrease in interaction between ketone (acetophenone) and 1-alkanols as well as between DMF and 1-alkanol, which eventually resulting in existence of weak molecular interactions in the present system of liquid mixtures.
\end{abstract}

Keywords: Adiabatic compressibility, Dipole-dipole interaction, Hydrogen bonding, Internal pressure, Intermolecular free length

\section{Introduction}

In recent years, the measurement of ultrasonic velocity has been adequately employed in understanding the nature of molecular interactions in pure liquids and liquid mixtures. The ultrasonic velocity measurements are highly sensitive to molecular interactions and can be used to provide qualitative information about the physical nature and strength of molecular interaction in the liquid mixtures ${ }^{1-3}$. Ultrasonic velocity of a liquid is fundamentally related to the binding forces between the atoms or the molecules and has been adequately employed in understanding the nature of molecular interaction in pure liquids ${ }^{4,5}$ binary and ternary mixture. The variation of ultrasonic velocity and related parameters throw much light upon the structural changes associated with the liquid mixtures having weakly interacting components $^{6-7}$ as well as strongly interacting components. 
The study of molecular association in organic ternary mixtures having alcohol as one of the components is of particular interest, since alcohols are strongly self-associated liquid having a three dimensional network of hydrogen bond ${ }^{8}$ and can be associated with any other group having some degree of polar attractions ${ }^{9}$. Although several investigations ${ }^{10-11}$, were carried out in liquid mixtures having alcohol as one of the components, a systematic study in a series of primary alcohols in ternary systems has been scarcely reported.

The ultrasonic studies for the binary mixtures of $N, N$-Dimethylformamide (DMF) with substituted benzenes ${ }^{12}$ with alcohols ${ }^{13-14}$ with branched alcohols ${ }^{15}$ with aliphatic esters ${ }^{16}$ with tetrahydrofuran ${ }^{17}$ with chloroethanes and chloromethanes ${ }^{18}$ and with vinylpyrrolidine ${ }^{19}$ are already reported in the literature. An exhaustive survey of literature has shown that a few attempts have been made for the ultrasonic velocity data of ternary mixtures ${ }^{20}$. However, no effort appears to have been made to collect the ultrasonic velocity data for the ternary mixtures of $N, N$-Dimethyformamide, (DMF) Acetophenone with 1-alkanols. Hence, the above literature survey has helped the authors which motivated them to carry out the present work. The present ternary liquid systems taken up by the authors for investigation at $303.15 \mathrm{~K}$ are

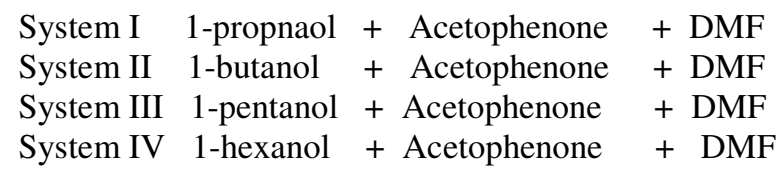

\section{Experimental}

In the present work, we have used chemicals, which are analytical reagent (AR) and spectroscopic reagent (SR) grades of minimum assay of $99.9 \%$ obtained from E-Merk, Germany and Sd fine chemicals, India. The purities of the above chemicals were checked and were compared with available literature values. The ternary liquid mixtures of different known composition were prepared by mole fraction basis. In all systems, the mole fraction of the second component, acetophenone $\left(X_{2}=0.2\right)$ was kept fixed while the mole fractions of the remaining two $\left(X_{1}\right.$ and $\left.X_{3}\right)$ were varied from 0.0 to 0.9 so as to have the mixtures of different compositions. The density was determined using a specific gravity bottle by relative measurement method. The weight of the sample was measured using a electronic digital balance with an accuracy of $\pm 0.1 \mathrm{mg}$ (Model: Shimadzu, Japan Make, AX-200). An Ostwald's viscometer $(10 \mathrm{~mL})$ was used for the viscosity measurement. Efflux time was determined by using a digital chronometer to within $\pm 0.001 \mathrm{~s}$. An Ultrasonic Interferometer having a frequency of $2 \mathrm{MHz}$ (Mittal Enterprises, New Delhi. Model: F-81) has been used for velocity measurement. The overall accuracy in the velocity measurement is $\pm 2 \mathrm{~ms}^{-1}$. An electronically digital operated constant temperature water bath (RAAGA Industries, Chennai) has been used to circulate water through the double walled measuring cell make up of steel containing the experimental solution at the desired temperature. The accuracy in the temperature measurement is $\pm 0.1 \mathrm{~K}$.

\section{Theory}

Various acoustical and thermodynamical parameters are calculated from the measured data such as

$$
\begin{aligned}
& \text { Adiabatic Compressibility } \beta=\frac{1}{\mathrm{U}^{2} \rho} \\
& \text { Intermolecular free length } L_{f}=K \sqrt{\beta}
\end{aligned}
$$


Where, $\mathrm{K}$ is a temperature dependent constant.

$$
\text { Free volume } V_{f}=\left(\frac{M_{\text {eff }} U}{K^{*} \eta}\right)^{3 / 2}
$$

Where $M_{\text {eff }}$ is the effective molecular weight $\mathrm{K}^{*}$ is a temperature independent constant for all liquids.

$$
\text { Internal Pressure } \pi_{i}=b R T\left(\frac{K \eta}{U}\right)^{1 / 2}\left(\frac{\rho^{2 / 3}}{M_{\text {eff }}^{7 / 6}}\right)
$$

Where, the terms have usual meaning. The Gibb's free energy can be estimated from the following relation.

$$
\Delta G=K T \ln \left(\frac{K T \tau}{h}\right)
$$

Where $\mathrm{K}$ is the Boltzmaan's constant and $\tau$ is the relaxation time. Excess values of the above parameters can be determined using

$$
A^{E}=A_{\text {exp }}-A_{i d}
$$

Where $_{A_{i d}}=\sum A_{i} X_{i}, A_{i}$ is any acoustical parameters and $X_{i}$ the molefraction of the liquid component.

\section{Results and Discussion}

The experimentally determined values of density $(\rho)$, viscosity $(\eta)$ and ultrasonic velocity $(\mathrm{U})$ of all the pure liquids at $303.15 \mathrm{~K}$ are presented in Table $1^{21-23}$ and the same for the ternary systems (I to IV) are listed in Table 2.

The values of adiabatic compressibility $(\beta)$, free length $\left(\mathrm{L}_{\mathrm{f}}\right)$, free volume $\left(\mathrm{V}_{\mathrm{f}}\right)$ and internal pressure $\left(\pi_{\mathrm{i}}\right)$, for the four liquid systems are reported at $303.15 \mathrm{~K}$ are given in Table 3, whereas, the Tables $4 \& 5$ summarise those excess values of some of these above parameters.

Table 1. Values of Density $(\rho)$, Viscosity $(\eta)$ and Ultrasonic Velocity (U) of pure organic liquids at $303.15 \mathrm{~K}$

\begin{tabular}{ccccccc}
\hline \multirow{2}{*}{$\begin{array}{c}\text { Organic } \\
\text { Liquids }\end{array}$} & \multicolumn{2}{c}{$\begin{array}{c}\text { Density } \\
\rho /\left(\mathrm{kg} \mathrm{m}^{-3}\right)\end{array}$} & \multicolumn{2}{c}{$\left.\begin{array}{c}\text { Viscosity } \\
\eta /\left(\mathrm{x}^{-3} 0^{-3}\right.\end{array} \mathrm{Nsm}^{-2}\right)$} & \multicolumn{2}{c}{$\begin{array}{c}\text { Ultrasonic Velocity } \\
\text { U/ms }\end{array}$} \\
\cline { 2 - 7 } & $\begin{array}{c}\text { Literature } \\
\text { Value }\end{array}$ & $\begin{array}{c}\text { Present } \\
\text { Value }\end{array}$ & $\begin{array}{c}\text { Literature } \\
\text { Value }\end{array}$ & $\begin{array}{c}\text { Present } \\
\text { Value }\end{array}$ & $\begin{array}{c}\text { Literature } \\
\text { Value }\end{array}$ & $\begin{array}{c}\text { Present } \\
\text { Value }\end{array}$ \\
\hline 1-Propanol & $800.1^{21}$ & 797.962 & $1.6111^{21}$ & 1.40018 & $1192^{21}$ & 1192 \\
1-Butanol & $804.4^{21}$ & 800.782 & $2.1502^{21}$ & 1.8146 & $1229^{21}$ & 1213 \\
1-Pentanol & $807.2^{21}$ & 806.825 & $2.7656^{21}$ & 2.3232 & $1253^{21}$ & 1255 \\
1-Hexanal & $810.2^{21}$ & 810.854 & $3.5130^{21}$ & 3.2259 & $1289^{21}$ & 1288 \\
$\begin{array}{c}\text { Acetophenone } \\
N . N \text {-Dimethyl } \\
\text { formamide (DMF) }\end{array}$ & $1019.7^{22}$ & 1017.52 & $1.532^{22}$ & 1.3433 & $1454^{22}$ & 1454 \\
\hline
\end{tabular}


The perusal of Table 2 exhibits that in all the four liquid systems, the ultrasonic velocity decreases with increase in mole fraction of alcohols. It is observed that as the number of hydrocarbon group or chain-length of alcohol increases, a gradual decrease in sound velocity is noticed. This behaviour at such concentrations is different from the ideal mixtures behaviour can be attributed to intermolecular interactions in the systems studied ${ }^{24-25}$. However, the adiabatic compressibility $(\beta)$ increases with increase of concentration as shown in Table 3. It is primarily the compressibility that increases due to structural changes of molecules in the mixture leading to a decrease in ultrasonic velocity ${ }^{26-27}$. Such a continuous increase in adiabatic compressibility with respect to the concentration of alkanols has been qualitatively ascribed to the effect of hydrogen bonding or dipole-dipole interactions $\mathrm{s}^{28}$.

Table 2. Values of density $(\rho)$, viscosity $(\eta)$ and ultrasonic velocity $(\mathrm{U})$ at $303.15 \mathrm{~K}$

\begin{tabular}{|c|c|c|c|c|}
\hline \multicolumn{2}{|c|}{ Mole fraction } & \multirow{2}{*}{$\begin{array}{r}\text { Density } \\
\rho /\left(\mathrm{kgm}^{-3}\right) \\
\end{array}$} & \multirow{2}{*}{$\begin{array}{c}\text { Viscosity } \\
\eta /\left(\times 10^{-3} \mathrm{Nsm}^{-2}\right)\end{array}$} & \multirow{2}{*}{$\begin{array}{c}\text { Ultrasonic } \\
\text { velocity } \mathrm{U} /\left(\mathrm{ms}^{-1}\right)\end{array}$} \\
\hline $\mathrm{X}_{1}$ & $\mathrm{X}_{3}$ & & & \\
\hline \multicolumn{5}{|c|}{ System - I : 1 - Propanol + Acetophenone $+N, N$-Dimethyl formamide (DMF) } \\
\hline 0.0000 & 0.7999 & 960.992 & 0.8759 & 1444 \\
\hline 0.1998 & 0.6002 & 937.357 & 0.9023 & 1412 \\
\hline 0.3997 & 0.3999 & 910.230 & 0.9460 & 1359 \\
\hline 0.5996 & 0.1998 & 885.117 & 1.0405 & 1318 \\
\hline 0.7999 & 0.0000 & 857.722 & 1.1910 & 1264 \\
\hline \multicolumn{5}{|c|}{ System - II : 1 - Butanol + Acetophenone $+N, N$-Dimethyl formamide (DMF) } \\
\hline 0.0000 & 0.8001 & 960.992 & 0.8759 & 1444 \\
\hline 0.1999 & 0.6002 & 932.119 & 0.93701 & 1401 \\
\hline 0.2849 & 0.5725 & 902.844 & 1.0229 & 1358 \\
\hline 0.6002 & 0.1996 & 877.463 & 1.1063 & 1311 \\
\hline 0.7955 & 0.0000 & 855.43 & 1.1951 & 1281 \\
\hline \multicolumn{5}{|c|}{ System -III : 1 - Pentanol +Acetophenone $+N, N$-Dimethyl formamide (DMF) } \\
\hline 0.0000 & 0.8000 & 960.992 & 0.8759 & 1444 \\
\hline 0.1999 & 0.6004 & 926.16 & 0.9656 & 1397 \\
\hline 0.4005 & 0.3997 & 899.62 & 1.2108 & 1365 \\
\hline 0.5998 & 0.1998 & 873.702 & 1.3620 & 1333 \\
\hline 0.8006 & 0.0000 & 849.933 & 1.7667 & 1307 \\
\hline \multicolumn{5}{|c|}{ System -IV : 1 - Hexanol +Acetophenone $+N, N$-Dimethyl formamide (DMF) } \\
\hline 0.0000 & 0.8000 & 960.992 & 0.8759 & 1444 \\
\hline 0.1999 & 0.6001 & 924.59 & 1.0239 & 1391 \\
\hline 0.3999 & 0.4004 & 895.18 & 1.2506 & 1361 \\
\hline 0.6000 & 0.1999 & 870.211 & 1.6087 & 1339 \\
\hline 0.7999 & 0.0000 & 849.933 & 2.1649 & 1317 \\
\hline
\end{tabular}

Alkanols are liquids which are associated through the hydrogen bonding and in the pure state, they exhibit equilibrium between the monomer and multimer species. Also, they can be associated with any other groups having some degree of polar attractions ${ }^{9}$. Similarly, $N-N$ dimethylformamide (DMF) is belonging to the amide group which is highly polar, aprotic solvent and its molecules are associated through dipolar interactions ${ }^{29}$. Mixing of DMF with alkanols would release the dipoles of alkanols due to the breaking of hydrogen bonds. As a result, the free dipoles released from the alkanols in association with DMF molecules forming strong hydrogen bonds, hence stronger molecular association existing between the 
DMF and alkanols molecules through hydrogen bonding ${ }^{28}$. Further, mixing of such DMF with 1-alkanols causes dissociation of hydrogen bonded structure of 1-alkanols and subsequent formation of (new) $\mathrm{H}$-bond $(\mathrm{C}=\mathrm{O}-\mathrm{H} \ldots . . \mathrm{O})$ between proton acceptor oxygen atom (with lone pair of electrons) of $\mathrm{C}=\mathrm{O}$ group of $\mathrm{DMF}$ and proton of $\mathrm{OH}$ - group of 1 -alkanols ${ }^{30}$.

As, 1-alkanols are associated through hydrogen bonding,

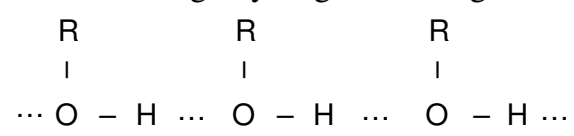

Acetophenone - 1-alkanols interactions are due to hydrogen bonding between the oxygen atom of the ketone and the proton of hydroxyl group of alkanols. The ultrasonic velocity in ternary liquid mixtures of $\mathrm{N}, \mathrm{N}$-dimethyl formaide in cyclohexanone with primary alcohols was investigated by Kannappan et al. ${ }^{23}$ and discussed in terms of hydrogen bond formation between the ketone and alcohols. Thirumaran et $a l .{ }^{31}$ also pointed out from their study of ternary mixtures of $N, N$-dimethyl acetamide (DMA) in cyclohexanone with 1 -alkanols that there is formation of hydrogen bonding between the ketone and 1-alkanols.

Further, the addition of $N, N$-Dimethylformamide (DMF) with mixtures causes dissociation of hydrogen bonded structure of 1-alkanols as well as decrease in interaction between ketone and alkanols leading to subsequent decrease in ultrasonic velocity. The subsequent formation of new hydrogen bonding between proton acceptor oxygen atoms of group of DMF and proton of $-\mathrm{OH}$ group of 1-alkanols ${ }^{30}[\mathrm{C}=\mathrm{O} \cdots \mathrm{H}-\mathrm{O}-]$.

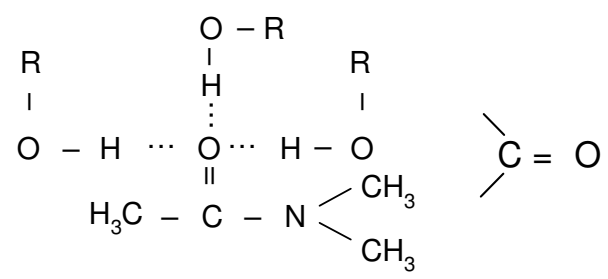

It is further observed that the same trend in free length too in all the three systems, as shown in Table 3. The increase in free length is due to the loose packing of the molecules inside the shield, which may be brought by weakening of molecular interactions ${ }^{32}$. In all the four liquid systems, free volume $\left(\mathrm{V}_{\mathrm{f}}\right)$ decreases with the increasing concentration of alcohols which are represented in Table 3. As discussed earlier, the dissociation of hydrogen bonded structure of 1-alkanols due to the mixing of DMF with it and subsequent formation of new bonds. Such a dissociation effect leads to a contraction in volume, which resulting an decrease in free volume. Further, the increasing trend of internal pressure $(\pi \mathrm{i})$ in all the four liquid systems with increasing concentration of alcohols, which are tabulated in Table 3 clearly supporting this prediction.

In order to understand the nature of molecular interactions between the components of the liquid mixtures, it is of interest to discuss the same in terms of excess parameter rather than actual values. Non-ideal liquid mixtures show considerable deviation from linearity in their physical behaviour with respect to concentration and these have been interpreted as arising from the presence of strong or weak interactions. The effect of deviation depends upon the nature of the constituents and composition of the mixtures. 
Table 3. Values of adiabatic compressibility $(\beta)$, free length $\left(\mathrm{L}_{\mathrm{f}}\right)$, free volume $\left(\mathrm{V}_{\mathrm{f}}\right)$ and internal pressure $\left(\pi_{\mathrm{i}}\right)$ at $303.15 \mathrm{~K}$

\begin{tabular}{|c|c|c|c|c|c|}
\hline \multicolumn{2}{|c|}{ Mole F } & \multirow{2}{*}{$\begin{array}{c}\text { Adiabatic } \\
\text { Compressibility } \\
\beta /\left(\times 10^{-10} \mathrm{~m}^{2} \mathrm{~N}^{-1}\right)\end{array}$} & \multirow{2}{*}{$\begin{array}{l}\text { Free length } \\
\mathrm{L}_{\mathrm{f}}\left(\times 10^{-10} \mathrm{~m}\right)\end{array}$} & \multirow{2}{*}{$\begin{array}{c}\text { Free Volume } \\
\mathrm{V}_{\mathrm{f}} \\
\left(\times 10^{-7} \mathrm{~m}^{3} \mathrm{~mol}^{-1}\right)\end{array}$} & \multirow{2}{*}{$\begin{array}{c}\text { Internal } \\
\text { Pressure } \pi_{\mathrm{i}} \\
\left(\times 10^{6} \mathrm{~N} \mathrm{~m}^{-2}\right)\end{array}$} \\
\hline $\mathrm{X}_{1}$ & $\mathrm{X}_{3}$ & & & & \\
\hline
\end{tabular}

System - I : 1 - Propanol + Acetophenone $+N, N$ - Dimethyl formamide (DMF)

$\begin{array}{llllll}0.0000 & 0.7999 & 4.9905 & 0.4573 & 1.7914 & 459.294 \\ 0.1998 & 0.6002 & 5.3508 & 0.4615 & 1.5802 & 481.164 \\ 0.3997 & 0.3999 & 5.9485 & 0.4866 & 1.3211 & 520.364 \\ 0.5996 & 0.1998 & 6.5038 & 0.5088 & 1.0389 & 557.180 \\ 0.7999 & 0.0000 & 7.2972 & 0.5389 & 0.7560 & 621.156\end{array}$

System - II : 1 - Butanol + Acetophenone $+N, N$-Dimethyl formamide (DMF)

$\begin{array}{llllll}0.0000 & 0.8001 & 4.9905 & 0.4457 & 0.1404 & 459.20 \\ 0.1999 & 0.6002 & 5.4657 & 0.4664 & 0.1217 & 471.163 \\ 0.2849 & 0.5725 & 6.0060 & 0.4880 & 0.1090 & 487.778 \\ 0.6002 & 0.1996 & 6.6307 & 0.5137 & 0.0792 & 520.516 \\ 0.7955 & 0.0000 & 7.1238 & 0.5320 & 0.0594 & 562.236\end{array}$

System -III : 1 - Pentanol +Acetophenone $+N, N$-Dimethyl formamide (DMF)

$\begin{array}{llllll}0.0000 & 0.8000 & 4.9905 & 0.4457 & 1.7916 & 459.21 \\ 0.1999 & 0.6004 & 5.5146 & 0.4685 & 1.5548 & 459.55 \\ 0.4005 & 0.3997 & 5.9658 & 0.4873 & 1.2640 & 489.35 \\ 0.5998 & 0.1998 & 6.4413 & 0.5064 & 0.9571 & 495.75 \\ 0.8006 & 0.0000 & 6.8875 & 0.5236 & 0.5181 & 538.45\end{array}$

System -IV : 1 - Hexanol +Acetophenone $+N, N$-Dimethyl formamide (DMF)

$\begin{array}{llllll}0.0000 & 0.8000 & 4.9905 & 0.4457 & 0.1403 & 455.359 \\ 0.1999 & 0.6001 & 5.5890 & 0.4717 & 0.1163 & 459.200 \\ 0.3999 & 0.4004 & 6.0307 & 0.4899 & 0.0918 & 462.094 \\ 0.6000 & 0.1999 & 6.4093 & 0.5051 & 0.0671 & 483.640 \\ 0.7999 & 0.0000 & 6.7833 & 0.5196 & 0.0456 & 521.370\end{array}$

The excess values of adiabatic compressibility $\left(\beta^{\mathrm{E}}\right)$, intermolecular free length $\left(\mathrm{L}_{\mathrm{f}}^{\mathrm{E}}\right)$, free volume $\left(\mathrm{V}_{\mathrm{f}}^{\mathrm{E}}\right)$, internal pressure $\left(\pi_{\mathrm{i}}^{\mathrm{E}}\right)$ Gibb's Free Energy $\left(\Delta G^{E}\right)$ and viscosity $\left(\eta^{E}\right)$ for all the four liquid systems are furnished in Tables $4 \& 5$. In the present investigation, one can observe that all the excess value parameters exhibit both positive as well as negative deviations over the entire range of composition in all four liquid systems. It is learnt that negative values of $\beta^{\mathrm{E}}$ is an indication of strong intermolecular interactions in the liquid mixtures, which is attributed to charge transfer, dipole-induced dipole and dipole-dipole interactions and hydrogen bonding. While positive excess values to weak interactions which result from dispersion forces. Rastogi ${ }^{27}$ shown from his studies of excess thermodynamic function in ternary mixtures that the addition of third component weakens the strength of the interaction and the ternary mixture tends to approach ideal behaviour. Further, it also suggested that the negative excess compressibility has been due to a closed packed molecules and positive excess values to weak interaction between unlike molecules. 
Table 4. Excess values of adiabatic compressibility $\left(\beta^{\mathrm{E}}\right)$, free length $\left(\mathrm{L}_{\mathrm{f}}^{\mathrm{E}}\right)$, free volume $\left(\mathrm{V}_{\mathrm{f}}^{\mathrm{E}}\right)$ and internal pressure $\left(\pi_{\mathrm{i}}^{\mathrm{E}}\right)$ at $303.15 \mathrm{~K}$

\begin{tabular}{|c|c|c|c|c|c|}
\hline \multicolumn{2}{|c|}{ Mole Fraction } & \multirow{2}{*}{$\begin{array}{l}\text { Excess Adiabatic } \\
\text { Compressibility } \\
\beta^{\mathrm{E}} /\left(\times 10^{-10} \mathrm{~m}^{2} \mathrm{~N}^{-1}\right)\end{array}$} & \multirow{2}{*}{$\begin{array}{l}\text { Excess Free } \\
\text { length } \mathrm{L}_{\mathrm{f}}^{\mathrm{E}} \\
\left(\times 10^{-10} \mathrm{~m}\right)\end{array}$} & \multirow{2}{*}{$\begin{array}{c}\text { Excess Free } \\
\text { Volume } \mathrm{V}_{\mathrm{f}}^{\mathrm{E}} \\
\left(\times 10^{-7} \mathrm{~m}^{3} \mathrm{~mol}^{-1}\right)\end{array}$} & \multirow{2}{*}{$\begin{array}{c}\text { Excess } \\
\text { Internal } \\
\text { Pressure } \pi_{\mathrm{i}}^{\mathrm{E}} \\
\left(\times 10^{6} \mathrm{Nm}^{-2}\right)\end{array}$} \\
\hline $\mathrm{X}_{1}$ & $X_{3}$ & & & & \\
\hline \multicolumn{6}{|c|}{ System - I : 1 - Propanol + Acetophenone $+N, N$-Dimethyl formamide (DMF) } \\
\hline 0.0000 & 0.7999 & -0.0399 & 0.0100 & -0.0405 & 313.069 \\
\hline 0.1998 & 0.6002 & -0.4181 & -0.0140 & 0.0397 & 140.461 \\
\hline 0.3997 & 0.3999 & -0.5566 & -0.0168 & 0.0725 & 108.568 \\
\hline 0.5996 & 0.1998 & -0.6875 & -0.0227 & 0.08217 & 12.5728 \\
\hline 0.7999 & 0.0000 & -0.7386 & -0.0210 & 0.0904 & -56.635 \\
\hline \multicolumn{6}{|c|}{ System - II : 1 - Butanol + Acetophenone $+N, N$-Dimethyl formamide (DMF) } \\
\hline 0.0000 & 0.8001 & -0.0410 & -0.0017 & -1.6919 & 312.934 \\
\hline 0.1999 & 0.6002 & -0.2375 & -0.0067 & -1.4152 & 210.805 \\
\hline 0.2849 & 0.5725 & -0.2766 & -0.0222 & -1.4096 & 170.1518 \\
\hline 0.6002 & 0.1996 & -0.4162 & -0.0113 & -0.8656 & 31.7346 \\
\hline 0.7955 & 0.0000 & -0.5574 & -0.0163 & -0.5888 & -37.355 \\
\hline \multicolumn{6}{|c|}{ System -III : 1 - Pentanol +Acetophenone $+N, N$-Dimethyl formamide (DMF) } \\
\hline 0.0000 & 0.8000 & -0.0405 & -0.0016 & -0.0405 & 313.3 \\
\hline 0.1999 & 0.6004 & -0.0661 & -0.0081 & 0.0219 & 211.75 \\
\hline 0.4005 & 0.3997 & -0.1646 & -0.0184 & 0.0323 & 139.696 \\
\hline 0.5998 & 0.1998 & -0.2326 & -0.0280 & 0.0256 & 44.984 \\
\hline 0.8006 & 0.0000 & -0.4379 & -0.0405 & -0.1139 & -14.435 \\
\hline \multicolumn{6}{|c|}{ System -IV : 1 - Hexanol + Acetophenone $+N, N$-Dimethyl formamide (DMF) } \\
\hline 0.0000 & 0.8000 & -0.0405 & -0.0016 & -1.6918 & 312.74 \\
\hline 0.1999 & 0.6001 & 0.0955 & 0.0058 & -1.4006 & 209.82 \\
\hline 0.3999 & 0.4004 & 0.0730 & 0.0053 & -1.1102 & 117.24 \\
\hline 0.6000 & 0.1999 & -0.0092 & 0.0022 & -0.8186 & 39.55 \\
\hline 0.7999 & 0.0000 & -0.0976 & -0.0017 & -0.5248 & -21.95 \\
\hline
\end{tabular}

Our present study depicts that the values of excess adiabatic compressibility $\left(\beta^{\mathrm{E}}\right)$ are negative for the first three liquid systems and it becomes negative on going to higher mole fraction range in system IV. However, the value of $\beta^{\mathrm{E}}$ decreases on further addition of alcohols in all the four systems and such a decreasing values suggest that the weakening of molecular interactions in the liquid mixtures. The Table 4 shows the variation of the excess free volume as a function of concentration in all systems. In the present investigation, the excess free volume values are positive in Systems I \& III and negative in II \& IV, which exhibit that the free volume in all the systems weaken due to hydrogen bonding interaction between ketone and alcohols and also due to dissociation of alcohol molecules. The observed positive values of excess free volume also suggest that the DMF - alkanols interaction is weaker than the alkanol-alkanol and alkanols-ketone interactions. The decreasing trend of positive excess values of internal pressure in all the four systems clearly confirms this.

One should observe from the Table 5, the variation of excess Gibbs energy $\Delta \mathrm{G}^{\mathrm{E}}$ for the four ternary liquid systems. The values of $\Delta \mathrm{G}^{\mathrm{E}}$ are all negative in all the systems concerned and increase with molar concentration of alcohols. According to Reed et al $^{33}$ the positive values of excess Gibbs energy values may be attributed to specific interactions like hydrogen bonding and charge transfer, while negative $\Delta \mathrm{G}^{\mathrm{E}}$ values may be ascribed to the dominance 
of dispersion forces. In the present investigation, our close observation suggests that the increasing negative values of $\Delta \mathrm{G}^{\mathrm{E}}$ shows that the strength of interaction gets weakened with increasing of 1-alkanols. According to Fort $e t$ al. ${ }^{34}$ the variation of excess viscosity $\left(\eta^{\mathrm{E}}\right)$ gives the strength of molecular interaction between the molecules.

Table 5. Excess values of excess Gibb's free energy $\left(\Delta G^{*}\right)$ and excess viscosity $\left(\eta^{\mathrm{E}}\right)$ at $303.15 \mathrm{~K}$

\begin{tabular}{|c|c|c|c|}
\hline \multicolumn{2}{|c|}{ Mole fraction } & \multirow{2}{*}{$\begin{array}{c}\text { Excess Gibb's free energy }\left(\Delta \mathrm{G}^{*} \mathrm{E}\right) \\
\left(\times 10^{-20} \mathrm{k} \mathrm{Jmol}^{-1}\right)\end{array}$} & \multirow{2}{*}{$\begin{array}{l}\text { Excess viscosity }\left(\eta^{\mathrm{E}}\right) \\
\left(\mathrm{x} 10^{-3} \mathrm{Nsm}^{-1}\right) \\
\end{array}$} \\
\hline $\mathrm{X}_{1}$ & $\mathrm{X}_{3}$ & & \\
\hline \multicolumn{4}{|c|}{ System - I : 1 - Propanol + Acetophenone $+N, N$-Dimethyl formamide (DMF) } \\
\hline 0.0000 & 0.7999 & -0.9507 & 0.0055 \\
\hline 0.1998 & 0.6002 & -0.8142 & -0.0961 \\
\hline 0.3997 & 0.3999 & -0.6543 & -0.1831 \\
\hline 0.5996 & 0.1998 & -0.4817 & -0.2179 \\
\hline 0.7999 & 0.0000 & -0.2826 & -0.1976 \\
\hline \multicolumn{4}{|c|}{ System - II : 1 - Butanol + Acetophenone $+N, N$-Dimethyl formamide (DMF) } \\
\hline 0.0000 & 0.8001 & -0.9510 & 0.00540 \\
\hline 0.1999 & 0.6002 & -0.8081 & -0.1458 \\
\hline 0.2849 & 0.5725 & -0.7827 & -0.1933 \\
\hline 0.6002 & 0.1996 & -0.4790 & -0.4016 \\
\hline 0.7955 & 0.0000 & -0.2964 & -0.5170 \\
\hline \multicolumn{4}{|c|}{ System -III : 1 - Pentanol +Acetophenone $+N, N$-Dimethyl formamide (DMF) } \\
\hline 0.0000 & 0.8000 & -0.9509 & 0.0055 \\
\hline 0.1999 & 0.6004 & -0.8983 & -4.2836 \\
\hline 0.4005 & 0.3997 & -0.8003 & -0.2889 \\
\hline 0.5998 & 0.1998 & -0.7476 & -0.4504 \\
\hline 0.8006 & 0.0000 & -0.6419 & -0.3619 \\
\hline \multicolumn{4}{|c|}{ System -IV : 1 - Hexanol +Acetophenone $+N, N$-Dimethyl formamide (DMF) } \\
\hline 0.0000 & 0.8000 & -0.9509 & 0.0055 \\
\hline 0.1999 & 0.6001 & -0.7985 & -0.3412 \\
\hline 0.3999 & 0.4004 & -0.6440 & -0.6092 \\
\hline 0.6000 & 0.1999 & -0.4729 & -0.7458 \\
\hline 0.7999 & 0.0000 & -0.2853 & -0.6841 \\
\hline
\end{tabular}

For systems, where dispersion, induction and dipolar forces which are operated by the values of excess viscosity are found to be negative, whereas the existence of specific interactions leading to the formation of complexes in liquid mixtures tends to make excess viscosity positive. In our present investigation, from Table 5 , the excess viscosity values are negative in all the four ternary liquid systems and decrease with the further addition of alkanols (except in System III) Hence, our present close observation of excess viscosity reveals that presence of weak dipolar forces are existing in the liquid mixtures. The possession of such negative values of $\eta^{\mathrm{E}}$ further suggests that the dominance of dispersive interaction resulting from the breaking up of the hydrogen bonds of alkanols resulting in weakening of molecular interactions in the liquid mixtures.

\section{Conclusion}

From ultrasonic velocity, related acoustical parameters and their excess values, we firmly conclude that the interaction between DMF and 1-alkanols is due to hydrogen bonding. We 
also further noticed that on further addition of DMF causes the rupturing of hydrogen bonded association of 1-alkanols and subsequent decrease in interaction between ketone (acetopheonone) and 1-alkanols as well as between DMF and 1-alkanols. Hence, it very obvious that existence of a weak molecular interaction prevails in the present system of liquid mixtures. No donor-acceptor complexities were identified in the present study.

\section{References}

1. Kincaid J F and Eyring H, J Chem Physics., 1937, 5, 587.

2. Mehta S K and Chauhan R K, J Solution Chem., 1996, 26, 295.

3. Dewan R K, Mehta S K, Parashar R. and Bala K, J Chem Soc Faraday Trans., 1991, 87, 1561.

4. Tabhane V A, Acoust Lett (G.B)., 1983, 6, 120.

5. Srinivasalu U and Ramachandra Naidu P, Indian J Pure Appli Phys., 1991, 29, 576.

6. Thirumaran S and Sathish K, Bull Pure Appl Sci., 2008, 27D(2), 239-248.

7. Thirumaran S and Karthikeyan N, Int J Chem Res., 2011, 3, 83-98.

8. Rowlison J S, Liquid and Liquid mixtures, $2^{\text {nd }}$ Edn., Butter Worths, London., 1969, 159.

9. Anwar Ali, Anil Kumar and Abida, J Chin Chem Soci., 2004, 51, 477-485.

10. Thirumaran S and Earnest Jayakumar J, Indian J Pure Appl Phys., 2009, 47, 265-272.

11. Thirumaran S, Earnest Jayakumar J and Hubert Dhanasundaram, E-J Chem., 2010, 7(2), 465-472.

12. Thirumaran S, Jayalakshmi K and Job Sabu K, Rasayan J Chem., 2009, 2(2), 424

13. Rao K P and Reddy K S, Physics Chem Liq., 1985, 15, 147.

14. Acree W E (Jr), Phys Chem Liq., 1986, 6, 113.

15. Rao K P and Reddy K S, Thermochimica Acta, 1985, 91, 321.

16. Rao K P and Reddy K S, Ultrasonics., 1990, 28, 120.

17. Prakash O and Sinha S, Acustica., 1984, 54, 223.

18. Alluraiah G, Ramajaneyulu K and Krishnaiah A, Pak J Sci Ind Res., 1989, 32, 370.

19. Naidu S V, Raju A V and Rao K C, J Polym Mater., 1990, 7, 149.

20. Thirumaran S and Saradha Devi S, Arch Appl Sci Res., 2009, 1(2), 128

21. Thirumaran S and Thenmozhi P, Asian J Appl Sci., 2010, 3(2), 153-159.

22. Thirumaran S and Savithri S, J Indian Chem Soc., 2010, 87, 279-287.

23. Kannappan A N, Thirumarnan S and Palni R, J Phy Sci., 2009, 20(2), 97-108.

24. Tiwari K, Patra C and Chakravathy V, Acoust Lett., 1995, 19, 53.

25. Kannappan A N and Palanniappan L, Indian J Physics., 1999, 73B, 531.

26. Nikam P S, Kapade V M and Mehdim Hasan, J Pure Appli Phys., 2001, 39, 433.

27. Rastogi M, Awasthi A, Guptha M and Shukla J P, Asian J Phys., 1998, 7, 739

28. Ali A, Hyder S and Nain A K, Indian J Phys., 2000, 74B (1), 63-67.

29. Vaslman I.I and Barkawitz M L, J Am Chem Soc., 1992, 114, 7889

30. Anwar Ali, Anil Kumar N, Dinesh Chand and Bhajan Lal, Indian J Pure Appl Phys., 2003, 41, 928 .

31. Thirumaran S and Ramesh J, Rasayan J Chem., 2009, 2(3), 733.

32. Arul G and Palaniappan L, J Acoust Soc Ind., 2000, 28, 393-395.

33. Reed T M and Taylor T E, J Phy Chem., 1959, 63, 58.

34. Fort R J and Moore W R, Trans Faraday Soc., 1965, 61, 2102. 